\title{
Hemostatic Abnormality and Associated Factors in Diabetic Patients at Jimma University Specialized Hospital, Jimma, Southwest Ethiopia: A Comparative Cross-sectional Study
}

\author{
Debebe Asrat ${ }^{1}$, GirumTesfaye ${ }^{2}$, Lealem Gedefaw ${ }^{2}$, Wondimagegn Addisu ${ }^{2}$, \\ TilahunYemane ${ }^{2}$
}

\section{OPEN ACCESS}

Citation: Debebe A,Girum T, Lealem G, Wodimagegn A, Tilahun Y. Hemostatic Abnormality and Associated Factors in Diabetic Patients at Jimma University Specialized Hospital, Jimma, Southwest Ethiopia: A Comparative Cross-sectional Study. Ethiop J Health Sci. 2018;29(2):251.

doi:http://dx.doi.org/10.4314/ ejhs.v29i2.12

Received: October 25, 2018

Accepted: November 22, 2018

Accepted: December 24, 2018

Published: March 1, 2019

Copyright: (C) 2019 Debele Asrat, et al. This is an open access article distributed under the terms of the Creative Commons Attribution License, which permits unrestricted use, distribution, and reproduction in any medium, provided the original author and source are credited.

Funding: Nil

Competing Interests: The authors declare that this manuscript was approved by all authors in its form and that no competing interest exists.

Affiliation and Correspondence:

${ }^{1}$ Manager of Universal Advanced

Clinical Laboratory, Jimma, Ethiopia

${ }^{2}$ School of Medical Laboratory

Sciences, Jimma University, Jimma, Ethiopia

*Email: girumtesfaye12@gmail.com

\begin{abstract}
BACKGROUND: Diabetes mellitus is a group of heterogeneous disorders of multiple etiologies characterized by chronic hyperglycemia resulting from defects in insulin secretion and/or insulin action. Diabetes mellitus has been reported to disturb normal hemostasis by various mechanisms. However, data on hemostasis of diabetic patients in the study area are lacking. This study was aimed at determining hemostatic profile and associated factors of hemostatic abnormality in diabetic patients.

METHODS: A comparative cross-sectional study was conducted involving a total of 238 (119 diabetic and 119 apparently healthy) individuals who came to the chronic care clinic, Jimma University Specialized Hospital. Socio-demographic and clinical data were collected through a structured questionnaire. A blood sample of $10 \mathrm{ml}$ was collected in EDTA (4ml), citrate (3ml) and chemistry (3ml) tubes to do platelet count, coagulation tests, and glucose and lipid profile analysis, respectively. Descriptive statistics as well as the median $\left(25^{\text {th }}\right.$, $75^{\text {th }}$ ) percentile and Mann Whitney $U$ test were used during data analysis.

RESULTS: The overall hemostatic abnormality in diabetes individuals was $58.8 \%$. The median (25th, 75th percentile) prothrombin time for diabetic and non-diabetic subjects was $(12.8,15.6)$ vs. (12.8, 14.2), respectively, and the difference was not statistically significant ( $p>0.05)$. The median $\left(25^{\text {th }}, 75\right.$ th percentile $)$ activated partial thromboplastin time was significantly different between the two groups $(p<0.0001)$; $(24,36.8)$ vs. $(36,39.6)$. The median $\left(25^{\text {th }}\right.$, 75 th percentile) fibrinogen level was significantly different between the two groups ( $p<0.0001) ;(277,462)$ vs. $(243,328)$. The median $\left(25^{\text {th }}, 75\right.$ th percentile) platelet count was also significantly different between the two groups $(p<0.0001) ;(146,248)$ vs. $(190,319)$. All variables were not significantly associated with hemostatic abnormality in multivariate regression analysis.

CONCLUSION: An overall hemostatic abnormality in diabetic patients was found to be high. The APTT and platelet count were lower in diabetic patients whilst the fibrinogen level was higher. Routine coagulation tests should be part of tests among diabetic patients. Advanced coagulation tests should also be considered to identify specific markers so as to pinpoint the particular problem.
\end{abstract}

KEYWORDS: Hemostasis, Diabetes Mellitus, Associated factors 


\section{INTRODUCTION}

Diabetes mellitus (DM) is a group of heterogeneous disorders of multiple etiologies characterized by chronic hyperglycemia resulting from defects in insulin secretion and/or insulin action (1). On the other hand, hemostasis is a normal body response which enables an organism to keep the blood in a fluid state, close off damaged blood vessels if vascular injury occurred, and remove blood clots after restoration of vascular integrity (2). There has been a body of evidence which suggests that diabetes mellitus can disturb normal hemostasis $(3,4)$. Hyperglycemia affects multiple steps of coagulation such as thrombus formation and inhibition, fibrinolysis, platelet, and endothelial function (5).

Increased platelet activity or enhanced activation and its mechanism in diabetes mellitus are evident in multiple studies. This is due to a combination of factors including the effects of insulin, hyperglycemia, hyperlipidemia, endothelial dysfunction, oxidative stress, and inflammatory state (6-8). High expression of GPIb (Glycoprotein Ib) and GPIIb/IIIa (Glycoprotein $\mathrm{IIb} / \mathrm{IIIa}$ ) for agonists and adhesive proteins on the platelet surface and increased fibrinogen binding was observed in diabetic patients (9).

Factor VII (FVII) levels increases in metabolic syndrome subjects and Type 2 DM patients which is related to the dyslipidemia is present in both conditions (10). Factor VIII is also increased in women with Type 2 DM which may not be due to the presence of endothelial dysfunction and/or an inflammatory process (11). Patients with Type 2 diabetes have a high prevalence of hyperfibrinogenemia, and fibrinogen level is independently associated with hemoglobin A1C values according to a study in India (12). These hemostatic disturbances in diabetes favor the hypercoagulate wing of hemostasis which in turn results in atherosclerosis and thrombosis. A study has shown that patients with diabetes are at high risk for myocardial infarction and stroke, with $75 \%$ of deaths secondary to cardiovascular complications (13).
Prothrombin time (PT), activated partial thromboplastin time (aPTT), platelet count, and fibrinogen level are global coagulation tests used to assess the coagulation system in a clinical setting. Patients with lower APTT are at increased risk for venous thromboembolism according to the Atherosclerosis Risk in Communities (ARIC), a study which investigated a-13-year risk of thromboembolism in relation to baseline APTT in 13,880 individuals (14).

Studies in other areas regarding coagulation profile in diabetic patients came up with a range of findings. Some studies showed that PT and APTT are significantly lower in diabetic than nondiabetic individuals $(15,16)$ while others showed that it is only APTT which is significantly lower in diabetic individuals as compared to the controls $(17,18,19)$.

There is scarcity of data on hemostasis in general population and DM patients in particular in Ethiopia. Therefore, the aim of this study was to determine hemostatic profile and associated risk factors of hemostatic abnormality in diabetic patients.

\section{MATERIAL AND METHODS}

Study setting: A comparative cross-sectional study was conducted from April 20 to May 10, 2014 in the Chronic Care Clinic, Jimma University Specialized Hospital. A total of 238 (119 diabetic and 119 apparently healthy individuals) were included in the study by convenient sampling technique. A Fsting blood sugar of $126 \mathrm{mg} / \mathrm{dl}$ and $110 \mathrm{mg} / \mathrm{dl}$ was used as a cut-off value for diabetic and non-diabetic group, respectively. Diabetic individuals who were on anticoagulant therapy, pregnant women, individuals with a history of venous thromboembolism or known inherited coagulation disorders, and with recent surgical procedure were excluded. Apparently healthy individuals who attended the laboratory for medical checkup and were negative for $\mathrm{C}$-reactive protein test were included in the non-diabetic group.

Data collection and laboratory testing: Sociodemographic and clinical data were collected using

DOI: http://dx.doi.org/10.4314/ejhs.v29i2.12 
structured questionnaire and checklist. Ten $\mathrm{ml}$ of 12 hours fasting venous blood was collected and transferred to EDTA tube $(4 \mathrm{ml}), 3.2 \%$ citrated tube $(3 \mathrm{ml})$ and plain tube $(3 \mathrm{ml})$. A Serum prepared from plain tube was used to determine glucose level and lipid profile by using Chemistry analyzer (HeCoS, Italy). C-reactive protein was determined based on CRP latex particles agglutination test method (CRP-turbidimetry, linear chemicals, S.L.) to recruit healthy individuals. Platelet poor plasma was prepared from the sample in the citrated tube after centrifuging at $1500 \mathrm{~g}$ for 15 minutes to analyze PT, APTT, and Fibrinogen level by a coagulation analyzer (Ares linear, Spain). EDTA tube sample was used to determine platelet count by making use of cell counter (HeCoS, Italy). The test was performed immediately after the collection of the sample.

Statistical analysis: Descriptive statistics was employed to determine frequency and percentage. The median (25th, 75th percentile) was used to compare hemostatic profiles between diabetic and non-diabetic individuals. The significance of the differences of medians between diabetics and nondiabetics were determined by using two-sample Wilcoxon rank-sum (Mann-Whitney) test. Factors associated with hemostatic profiles in diabetics and apparently healthy non-diabetic individuals were determined by binary logistic regression analysis controlling for confounding variables. Odds ratio, and its $95 \%$ confidence interval was reported. $P$-value of less than $5 \%(\mathrm{p}<0.05)$ was taken as statistically significant.

Ethics: Ethical approval was obtained from the Ethical Review Committee of Jimma University Institute of Health. Written informed consent was obtained from each participant after a clear explanation of the purpose of the study, the procedure, benefits and possible discomfort and the right to voluntary participation. Confidentiality was mainstsined for any information obtained from participants during the study.

\section{RESULTS}

Demographic and clinical data: A total of 238 individuals were involved in the study, 119 in each group. Among the 119 diabetes patients, $67(57.3 \%)$ were males while in non-diabetics, $50(42.7 \%)$ were males. The majority of the diabetic patients were within the age group of 40$65(78.2 \%)$ years. The majority of DM participants had attended primary education 36(36.4\%) (Table1).

Table 1: Reference ranges used for hemostatic parameters in the study.

\begin{tabular}{ll}
\hline Hemostatic parameters & Reference ranges \\
\hline PT & $10-15$ seconds \\
APTT & $25-43$ seconds \\
Fibrinogen Level & $200-400 \mathrm{mg} / \mathrm{dl}$ \\
Platelet count & $150-400 \times 10^{3} / \mu 1$ \\
\hline
\end{tabular}

Female participants in both groups were not using oral contraceptive. Type 2 DM was $97(81.5 \%)$ of the diabetics, and the mean duration of diabetes was $8( \pm 3.4)$ years. Out of the 119 diabetics, $33(27.7 \%)$ had complications such as neuropathy $(4(3.4 \%))$, retinopathy $(18(15 \%))$, chronic kidney disease $(19(16 \%))$, and chronic heart disease $(5(4 \%))$. Diabetic patients were categorized into two groups depending on the fasting blood sugar (FBS) values i.e. $70-130 \mathrm{mg} / \mathrm{dl}$ (good control) and $\geq 130 \mathrm{mg} / \mathrm{dl}$ (poor control). The mean FBS level was $(227.9 \pm 87.5) \mathrm{mg} / \mathrm{dl}$, and the majority, 104(87.4\%), were in uncontrolled FBS level (Table 2).

Table 2: Clinical Data of diabetic individuals at JUSH chronic care center, southwest Ethiopia, from April to June 2014.

\begin{tabular}{lcc}
\hline \multicolumn{1}{c}{ Variables } & No (\%) \\
\hline Type of diabetes & Type 1 & $22(18.5)$ \\
& Type 2 & $97(81.5)$ \\
Duration of & $<8$ years & $72(60.5)$ \\
diabetes & & \\
& $\geq 8$ years & $47(39.5)$ \\
DM Complication & Yes & $33(27.7)$ \\
Control of FBS & No & $86(72.3)$ \\
& Good control & $15(12.6)$ \\
Hypertension & Poor control & $104(87.4)$ \\
& Yes & $42(35.3)$ \\
Body Mass Index & No & $77(64.7)$ \\
& Normal & $57(47.8)$ \\
& Abnormal(obese) & $62(52.0)$ \\
\hline
\end{tabular}


Hemostatic profile: The overall hemostatic abnormality in diabetes was $70(58.8 \%)$ while in non-diabetic individuals, it was $19(16 \%)$. The analysis has showed that the $25^{\text {th }}$ median and the $75^{\text {th }}$ percentile of PT were not significantly different between diabetics and non-diabetics ( $p>$ 0.05 ) whilst the 25 th, median and 75 th percentile of APTT, platelet count and fibrinogen level were significantly different between the two groups $(p<0.0001)$. A significant difference was observed between the groups in the overall hemostatic abnormality $(\mathrm{P}<0.001)$ and fibrinogen accounts for the highest proportion (Table 3 ).

Table 3: Comparison of the hemostatic profiles of diabetic and non-diabetic subjects

\begin{tabular}{|c|c|c|c|c|c|c|c|c|c|c|c|}
\hline \multirow{2}{*}{$\begin{array}{l}\text { Hemostasis } \\
\text { parameters }\end{array}$} & \multicolumn{5}{|c|}{ Diabetic patients $(n=119)$} & \multicolumn{5}{|c|}{ Non diabetic patients $(\mathrm{n}=119)$} & \multirow{2}{*}{$p . v a l u e$} \\
\hline & $\begin{array}{l}\text { Norma } \\
1 \\
\text { No (\%) }\end{array}$ & $\begin{array}{l}\text { Abnormal } \\
\text { No }(\%)\end{array}$ & $\begin{array}{l}\text { Median } \\
*\end{array}$ & $\begin{array}{l}25^{\text {th }} \text { percentil } \\
\mathrm{e}\end{array}$ & $\begin{array}{l}75^{\text {th }} \\
\text { percentile }\end{array}$ & $\begin{array}{l}\text { Norma } \\
1 \\
\text { No(\%) }\end{array}$ & $\begin{array}{l}\text { Abnorma } \\
1 \\
\text { No (\%) }\end{array}$ & $\begin{array}{l}\text { Media } \\
\mathrm{n}\end{array}$ & $\begin{array}{l}25^{\text {th }} \\
\text { percentil } \\
\mathrm{e}\end{array}$ & $\begin{array}{l}75^{\text {th }} \text { percentil } \\
\mathrm{e}\end{array}$ & \\
\hline PT(second) & $85(71.4$ & $34(28.6)$ & 13.7 & 12.8 & $\begin{array}{l}15 . \\
6\end{array}$ & $108(90.7)$ & )$^{11(9.3}$ & 13.6 & 12.8 & 14.2 & 0.09 \\
\hline $\begin{array}{l}\text { APTT } \\
\text { (seconds) }\end{array}$ & $86(72.3$ & $33(27.7)$ & 31 & 24 & $\begin{array}{l}36 . \\
8\end{array}$ & $117(98.3$ & $2(1.7)$ & 35.9 & 32 & 39.6 & $\begin{array}{l}<0.000 \\
1\end{array}$ \\
\hline $\begin{array}{l}\text { Fibrinogen } \\
(\mathrm{mg} / \mathrm{dl})\end{array}$ & $67(56.3$ & $52(43.7)$ & 387 & 277 & 462 & $110(92.4)$ & $9(7.6)$ & 286 & 243 & 328 & $\begin{array}{l}<0.000 \\
1\end{array}$ \\
\hline $\begin{array}{l}\text { PLT } \\
\left(10^{3} / \mu \mathrm{I}\right)\end{array}$ & $84(70.6$ & $35(29.4)$ & 199 & 146 & 248 & $116(97.4)$ & $3(2.6)$ & 238 & 190 & 319 & $\begin{array}{l}<0.000 \\
1\end{array}$ \\
\hline Total & $49(41.2$ & $70(58)$. & & & & $100(84.0)$ & $19(16)$ & & & & $\begin{array}{l}<0.000 \\
1\end{array}$ \\
\hline
\end{tabular}

Associated factors: The main biochemical characteristics of diabetes patients and te control group are summarized in Table 4. In the multivariate logistic regression, there were no significant associations between plasma levels of total cholesterol (TC), triglycerides (TG), HDLcholesterol, and hemostatic abnormality. In the bivariate logistic regression analysis, age, residence, duration of DM, uncontrolled FBS level, hypertension, obesity, and high LDL (low density lipid) were significantly associated with hemostatic abnormality in diabetic individuals. Following adjustment in a multivariate regression model, none of the variables were significantly associated with hemostatic abnormality. 
Table 4: Hemostatic abnormality and associated factors in diabetic patients

\begin{tabular}{|c|c|c|c|c|c|c|}
\hline \multirow[t]{2}{*}{ Variable } & \multicolumn{2}{|c|}{ Hemostasis Abnormality } & \multirow[t]{2}{*}{ COR (95\% C. I) } & \multirow[t]{2}{*}{ P-Value } & \multirow[t]{2}{*}{ AOR (95\% C. I) } & \multirow[t]{2}{*}{ P-value } \\
\hline & Normal & Abnormal & & & & \\
\hline \multicolumn{7}{|l|}{ Age } \\
\hline $18-39$ & $19(52.8)$ & $17(47.2)$ & -- & & & \\
\hline $40-64$ & $24(35.3)$ & $44(64.7)$ & $4.368(2.44-7.82)$ & 0.000 & $2.143(.613 .491)$ & 0.232 \\
\hline$>\quad 65$ & $6(40)$ & $9(60)$ & $5.08(1.67-15.38)$ & 0.000 & $1.426(.26-7.81)$ & 0.682 \\
\hline \multicolumn{7}{|c|}{ 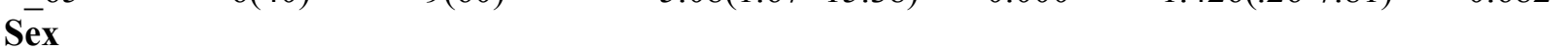 } \\
\hline $\mathrm{M}$ & $29(43.3)$ & $38(56.7)$ & $1.175(0.69-1.98)$ & 0.547 & & 0.547 \\
\hline $\mathrm{F}$ & $20(38.5)$ & $32(61.5)$ & & & & \\
\hline \multicolumn{7}{|l|}{ Location } \\
\hline Urban & $22(40)$ & $33(60)$ & - & & & \\
\hline Rural & $27(42.2)$ & $37(57.8)$ & $1.707(1.00-2.90)$ & 0.048 & $.994(.38-2.54)$ & 0.990 \\
\hline \multicolumn{7}{|l|}{ Education } \\
\hline Illiterate & $10(37)$ & $17(63)$ & $1.417(0.29-6.81)$ & 0.664 & & 0.664 \\
\hline Read\& write & $9(34.6)$ & $17(65.4)$ & $0.595(0.13-2.62)$ & 0.492 & & 0.492 \\
\hline Pre. school & $16(44.4)$ & $20(55.6)$ & $0.41(0.09-1.77)$ & 0.234 & & 0.234 \\
\hline Sec. school & $10(45.5)$ & $12(54.5)$ & 0.65( & 0.582 & & 0.582 \\
\hline $\begin{array}{l}\text { Above } \\
\text { secondary }\end{array}$ & $4(50)$ & $4(50)$ & - & - & & \\
\hline \multicolumn{7}{|l|}{ Type of DM } \\
\hline Type I & 13(59.1) & $9(40.9)$ & & & & \\
\hline Type II & $36(37.1)$ & $61(62.9)$ & $2.448(0.95-6.29)$ & 0.063 & $0.55(.110-2.76)$ & 0.469 \\
\hline \multicolumn{7}{|l|}{ FBS level } \\
\hline controlled & $15(100)$ & $0(0)$ & - & & & \\
\hline uncontrolled & $34(32.7)$ & $70(67.3)$ & $12.74(6.5-24.85)$ & 0.000 & $3.787 \mathrm{E} 9(0.00$ & 0.998 \\
\hline \multicolumn{7}{|c|}{ Duration DM } \\
\hline$<\_8$ years & $35(48.6)$ & $37(51.4)$ & -- & & & \\
\hline$>\overline{8}$ years & $14(29.8)$ & $33(70.2)$ & $2.230(1.02-4.85)$ & 0.043 & $1.72(0.63-4.67)$ & 0.288 \\
\hline \multicolumn{7}{|c|}{ DM complication } \\
\hline Yes & $11(33)$ & $22(66.7)$ & $1.583(0.68-3.66)$ & 0.283 & & \\
\hline No & $38(44)$ & $48(56)$ & -- & & & \\
\hline \multicolumn{7}{|c|}{ Blood Pressure } \\
\hline High & $12(29)$ & $30(71)$ & $2.31(1.03-5.17)$ & 0.041 & $2.18(.79-6.02)$ & 0.131 \\
\hline Normal & $37(48)$ & $40(52)$ & -- & & & \\
\hline \multicolumn{7}{|c|}{ Body Mass Index } \\
\hline Normal & $27(47)$ & $30(53)$ & & & & \\
\hline Abnormal & $22(35)$ & $40(65)$ & $2.610(1.49-4.55)$ & 0.001 & $1.58(0.58-4.33)$ & 0.366 \\
\hline \multicolumn{7}{|c|}{ Total Cholesterol mg/dl } \\
\hline$<2001$ & $36(48)$ & $39(52)$ & & & & \\
\hline$>\overline{2} 00$ & $12(28)$ & $31(72)$ & $2.201(0.99-4.85)$ & 0.050 & $1.482(.53-4.16)$ & 0.456 \\
\hline \multicolumn{7}{|c|}{ Triglycerides mg/dl } \\
\hline$<+150$ & $8(62)$ & $5(38)$ & & & & \\
\hline$>\overline{1} 50$ & $41(39)$ & $65(61)$ & $2.537(0.778 .28)$ & 0.123 & $1.764(.38-8.02)$ & 0.463 \\
\hline \multicolumn{7}{|l|}{ HDL mg/dl } \\
\hline$>\quad 40$ & $49(42)$ & $68(58)$ & & & & \\
\hline$<\overline{4} 0$ & $0(0)$ & $2(100)$ & $5.163(0.53-50.4)$ & 0.163 & 8.433E8(.000- & 0.999 \\
\hline LDL mg/dl & & & & & & \\
\hline
\end{tabular}

DOI: http://dx.doi.org/10.4314/ejhs.v29i2.12 


\begin{tabular}{lllllll}
\hline$<100$ & $38(48)$ & $41(52)$ & & & & \\
$>100$ & $11(27.5)$ & $29(72.5)$ & $3.948(2.02-7.71)$ & 0.000 & $0.29(0.45-0.10)$ & 0.298 \\
\hline
\end{tabular}

\section{DISCUSSION}

The overall hemostatic abnormality in diabetics was higher than in the non-diabetics. The median (25th, 75th percentile) APTT, fibrinogen level and platelet count were significantly different between the two groups while PT has showed no significant difference between the groups.

PT and APTT tests are standard screening tests for function of the coagulation system, and their utility in monitoring therapeutic anticoagulation is widely accepted. A multicenter cohort study showed that baseline APTT below the median was associated with increased risk of future venous thromboembolism after adjustment for demographic factors and relevant hemostatic factors (14). In this study, the APTT in the diabetic patients showed a shortened value as compared to the non-diabetics, and the median (25th, 75th percentile) was significantly different between the two groups. This finding is in agreement with the study done in Tribhuvan University Teaching Hospital (TUTH) which showed that there was a decrease in the value of APTT in diabetics than nin on-diabetics; the difference was statistically significant (17). A similar finding was observed in the study done in China. Statistically significant difference was observed in the APTT when the high-risk diabetic group was compared with the normal group (18). The same is true for the study in Turkey which revealed that there was significantly shortened APTT in both diabetic group and impaired fasting glucose (IFG) group as compared to the euglycemic group (19). Mean prothrombin time (PT) and activated partial thromboplastin time (APTT) levels were significantly $(\mathrm{P}<0.001)$ lower in patients with diabetes mellitus than those of control groups according to the study done in Dhaka Medical college, Bangladesh (20).

Fibrinogen level is useful as part of the investigation of bleeding tendency or an unexplained prolongation of the APTT or PT. Elevated levels may correlate with increased risk of thrombosis in epidemiological studies although the significance in individual patients is unclear (21). In this study, PT was not significantly different between the two groups while fibrinogen level showed a significant difference, higher in the diabetic group. This is in accordance with the study done in India which showed that there was a rise in plasma fibrinogen levels in diabetics as compared to controls (22). Another study done in India showed the same result which is an increased serum fibrinogen level in all diabetic patients as compared to non-diabetic controls (23). It was also seen that in the diabetic subset, the plasma fibrinogen levels were significantly higher than the non-diabetic subset in another study (12).

Platelets of diabetic individuals have abnormal tendency of increased activity and aggregation which lead to thrombus formation of microcapillary embolization and local vascular lesions (24). The median platelet count showed statistically significant difference between diabetics and non-diabetics. This is in agreement with the study done by Hekismoy et al. which showed that the mean platelet counts were significantly lower in diabetics as compared to age- and sex-matched non-diabetic healthy controls (25).

In conclusion, overall hemostatic abnormality in diabetic patients was found to be high. The PT value revealed no statistical difference between the two groups. The APTT and platelet count were lower in diabetic patients whilst the fibrinogen level was higher. This study recommends that routine coagulation tests should be part of tests in diabetic patients during followup along with clinical diagnosis. Advanced coagulation tests should also be considered by future studies to identify specific markers so as to identify particular problems in this group of individuals.

DOI: http://dx.doi.org/10.4314/ejhs.v29i2.12 


\section{ACKNOWLEDGMENTS}

We would like to thank all the study participants for taking part in the study. We also sincerely thank Jimma University for funding the study.

\section{REFERENCES}

1. Association AD Diagnosis and classification of diabetes mellitus. Diabetes Care. 2009;32(Suppl. 1): S62-S67.

2. Versteeg HH, Heemskerk JW, Levi M, Reitsma PH. New fundamentals in hemostasis. Physiol Rev. 2013;93(1):327-58.

3. Fayeza K, Qazi SA, Shamima J, et al. Coagulation Impairment in Type 2 Diabetes Mellitus. J Bangladesh Soc Physiol. 2015; 10(1): 26-29.

4. Dhule SS, Gawali SR. Platelet aggregation and clotting time in type II diabetic males. Natl J Physiol Pharm Pharmacol 2014; 4:121-123.

5. Ceriello A. Coagulation activation in diabetes mellitus: the role of hyperglycemia and therapeutic prospects. Diabetologia. 1993;36:1119-1125.

6. Zhu W, Li W, Silverstein RL. Advanced glycation end products induce a prothrombotic phenotype in mice via interaction with platelet CD36. Blood. 2012; 119 (25):6136-6144.

7. Ferreiro JL, Gómez-Hospital JA, Angiolillo DJ. Platelet abnormalities in diabetes mellitus. DiabVasc Dis Res. 2010; 7(4):251259.

8. Nicholaos K, Jeffrey JR, Antonios K, Jon RR. Platelet Function in Patients with Diabetes Mellitus: From a Theoretical to a Practical Perspective. International Journal of Endocrinology, 2011; DOI:10.1155/2011/742719

9. Mojka.S. International Federation of Clinical Chemistry and Laboratory Medicine. Disturbances of hemostasis in diabetes mellitus contributing to the development of atherosclerosis, 2002.

10. Anna LS, Marinez OS, Ana PS, Moura F, Maria GC. Hemostatic changes in patients with type 2 diabetes mellitus. Rev. Bras.
Hematol. Hemoter.2010; 32:6.

11. Soares AL, Kazmi RS, Borges MA, Rosário PW, Fernandes AP, Sousa MO. Elevated plasma factor VIII and von Willebrand factor in women with type 2 diabetes: inflammatory reaction, endothelial perturbation or else? Blood Coagul Fibrinolysis. 2011; 22(7):600605.

12. Gupta $\mathrm{P}$, Bhambani $\mathrm{P}$, Narang S. Study of plasma fibrinogen level and its relation to glycemic control in type- 2 diabetes mellitus patients attending diabetes clinic at a tertiary care teaching hospital in Madhya Pradesh, India. Int J Res Med Sci. 2016;4:3748-3754.

13. Carr ME. Diabetes mellitus: A hypercoagulable state. $J$ Diabetes Complications. 2001;15:44-54.

14. Zakai NA, Ohira T, White R, Folsom AR, Cushman M. Activated partial thromboplastin time and risk of future venous thromboembolism. $A m \quad J \quad$ Med. 2008;121(3):231-238.

15. Richard KD, Yaw A, Patrick A, Lord TW, Prince A, Solomon P, et al. High risk of coagulopathy among Type-2 Diabetes Mellitus clients at a municipal hospital in Ghana. Ghana Med J. 2017 Sep; 51(3): 101.

16. Ankalayya B, Sodhi HS, Sudhir M,Manisha B. A comparative study of coagulation time in type 2 Diabetes Mellitus and healthy individuals. IJCMR. 2016; 3(11): 3170-71.

17. Sapkota B, Shrestha SK, Poudel S .Association of activated partial thromboplastin time and fibrinogen level in patients with type II diabetes mellitus. $B M C$ Research Notes. 2013; 6:485.

18. Zhao Y, Zhang J, Zhang J, Wu J. Diabetes Mellitus Is Associated with Shortened Activated Partial Thromboplastin Time and Increased Fibrinogen Values. PLOS ONE. 2011; 6(1): e16470.

19. Alev K, Hatice S, Aysun T, Rana T, Macit K. Association Between Fasting Plasma Glucose and Routine Coagulation Tests. Tip AraştırmalarıDergisi. 2013: 11(3):99-102.

20. Fayeza K, Qazi SA, Shamima J, et al. Coagulation Impairment in Type 2 Diabetes Mellitus. J Bangladesh Soc Physiol. 2015; 10(1): 26-29.

DOI: http://dx.doi.org/10.4314/ejhs.v29i2.12 
21. A practical guide to laboratory Hemostasis accessed from http://www.practicalhaemostasis.com/Screening\%20Tests/fibrino gen.html October 16, 2018.

22. Desai K.N.P., Roopakala M.S., Silvia C.R.W.D.Kumar KMP. Evaluation of plasma fibrinogen levels in type 2 diabetes mellitus. Int J Diabetes DevCtries. 2012; 32: 209-213.

23. Sanjay D, Satyam J, Anil KG. Serum fibrinogen level in type 2 diabetes mellitus patients. Int J Adv Med. 2016;3(1):83-87.

24. Kakouros N, Rade JJ, Kourliouros A, Resar JR: Platelet function in patients with diabetes mellitus: from a theoretical to a practical perspective. Int J Endocrinol. 2011: 742719.

25. Hekimsoy Z, Payzin B, Ornek T, Kandoğan G. Mean platelet volume in Type 2 diabetic patients. $J$ Diabetes Complications. 2004;18(3):173-176.

DOI: http://dx.doi.org/10.4314/ejhs.v29i2.12 